Original Article

\title{
Clinical Outcome and Complication of Endoscopic Endonasal Transsphenoidal Surgery (ETSS) for Pituitary Adenoma: Retrospective Study at Prime Teaching Hospital Peshawar
}

\author{
Musawer Khan ${ }^{1}$, Arif Hussain ${ }^{2}$, Mumtaz Ali $^{2}$ \\ ${ }^{1}$ Mardan Medical Complex, Teaching Hospital, Mardan, Pakistan \\ ${ }^{2}$ Department of Neurosurgery, Prime Teaching Hospital, Peshawar - Pakistan
}

\section{ABSTRACT}

Objectives: The study aimed to ascertain the clinical outcome and complications of endoscopic endonasal transsphenoidal surgery (ETSS) for pituitary adenomas.

Material \& Methods: A retrospective study conducted at the Department of Neurosurgery Prime Teaching Hospital Peshawar, Pakistan. Pituitary adenoma was diagnosed in 89 patients on MRI Brain with contrast and post-surgical biopsy. Post-surgical outcomes and complications were documented.

Results: Out of 89 patients, $54 \%$ were male, and $46 \%$ female patients. The mean age was $42 \pm 5$ years. Headache was reported in $92 \%$ as a most common presentation, followed by decreased visual acuity in $62 \%$, amenorrhea in $22 \%$, and acromegaly in $29 \%$ of patients. Overall, the symptoms related to surgical improvement were observed in $72 \%$ of patients. A good surgical outcome was observed in $80 \%$ of patients with microadenomas, as compared to the patients with macroadenomas. The most common complication was the transient diabetes insipidus followed by Cerebrospinal fluid (CSF) leak and post-operative hematoma.

Conclusion: Endoscopic endonasal transsphenoidal surgery (ETSS) is a safe, less invasive, cosmetically effective technological advancement for pituitary adenomas.

Keywords: Endoscopic endonasal transsphenoidal surgery (ETSS), Pituitary adenoma, Diabetes insipidus, Microadenomas, Macroadenomas.

\section{Corresponding Author: Musawer Khan \\ Department of Neurosurgery, Mardan Medical Complex, Mardan, Pakistan \\ Email: modestgaze@yahoo.com}

Date of Submission: 01-03-2021

Date of Revision: 25-03-2021

Date of Online Publishing: 31-03-2021

Date of Print: 31-03-2021

DOI: $10.36552 /$ pjns.v25i1.520

Pak. J. of Neurol. Surg. - $2021-25$ (1): 57-62.

\section{INTRODUCTION}

Globally, the overall incidence of pituitary adenomas is around $17 \%{ }^{1}$ Transsphenoidal surgery (TSS) is a very safe and effective surgical approach for most pituitary micro and macro adenomas, and is offered as a first choice surgery in most patients with Pituitary Adenoma except for the Prolactinomas responsive to dopamine agonists. Treatments such as radiotherapy or

http//www.pakjns.org 
stereotactic radiosurgery may be offered to those patients who don't benefit from surgery. ${ }^{2}$

Transsphenoidal surgery for pituitary adenomas has a very low incidence of complications and even lower mortality. Transient diabetes insipidus due to CSF leak and post-op hematoma is a complication that is apprehended. The mortality rate has also been reported very low and the complication rate is acceptable. The prevalence of complications after endoscopic TSS has been reported between $3-36 \%$, which are mostly due to the CSF leak, dysfunction of the anterior lobe, and diabetes insipidus (DI). ${ }^{3-4}$ Rehman et al $(2018)^{4}$ reported around $31 \%$ complications from TSS.

Endoscopic transsphenoidal surgery (ETSS) for pituitary adenomas is superior to microscopic approach in the treatment of large sized pituitary adenomas. The postoperative complications are comparable. However, in increased tumor size, the success rate can be lower in both approaches owing to lateral extension and invasion of the cavernous sinus. ${ }^{2,5}$ Pituitary adenomas were most effectively addressed and the treatment was most rewarding when it is detected early followed by rendering prompt and relevant treatment. In another study, it has been concluded that endoscopic transsphenoidal surgery is an effective and safe modality for pituitary adenoma's treatment and can be employed as a first-choice therapy. ${ }^{6-7}$ The objective of the current study was to report the efficacy, safety, clinical outcomes and complications of endoscopic endonasal transsphenoidal techniques for pituitary adenomas.

\section{MATERIAL AND METHODS}

\section{Study Design \& Setting}

A retrospective observational study of 3 years from was carried out in the Department of Neurosurgery Prime Teaching Hospital Peshawar, Pakistan. Total of 89 patients was included.

\section{Inclusion Criteria}

Patients of both genders of ages between 15 to 70 years were included. Patients with Sellar Suprasellar tumor were included who were amenable to endoscopic approach.

\section{Exclusion Criteria}

Cases of the recurrent tumors were excluded. Those patients were also excluded who were not fit for surgery.

\section{Endoscopic Endonasal Transsphenoidal Surgery (ETSS) - Pituitary Adenomas}

The patient was placed in the supine position with head raised at 30 degrees. The approach was through the ipsilateral nostril, traversing the middle turbinate and to the sphenoid sinus. The ETSS approach was incorporated with endoscopic visualization. Paraseptal approach (between midturbinate and nasal septum) was utilized via. patient's nasal air-passage. ${ }^{8}$

The whole procedure benefitted from endoscopic visualization. Use of the endoscope through the middle turbinates required a small incision in the back of the nasal septum. We used surgical chisels and drills to cut through the bony wall and sinus. ${ }^{8}$ The sphenoid sinus was opened to reach the gland and excision of the tumor carried out. There were advantages of going through the transsphenoidal approach. The brain was not touched and so the chances of brain injury were extremely low. This approach leaves no scar. However, transsphenoidal surgery takes a longer time and it's hard to take out large tumors through this approach. ${ }^{7,9}$ Figure 1 showing an axial view MRI brain T2 weighted image showing large pituitary adenoma. Figure $\mathbf{2}$ shows a sagittal MRI with contrast showing Sellar Suprasellar mass.

\section{Data Collection}

Pituitary adenoma was diagnosed on MRI Brain 
with contrast and post-surgical biopsy. Background and clinical information were collected through a designed proforma. Surgical outcomes and complications were noted and

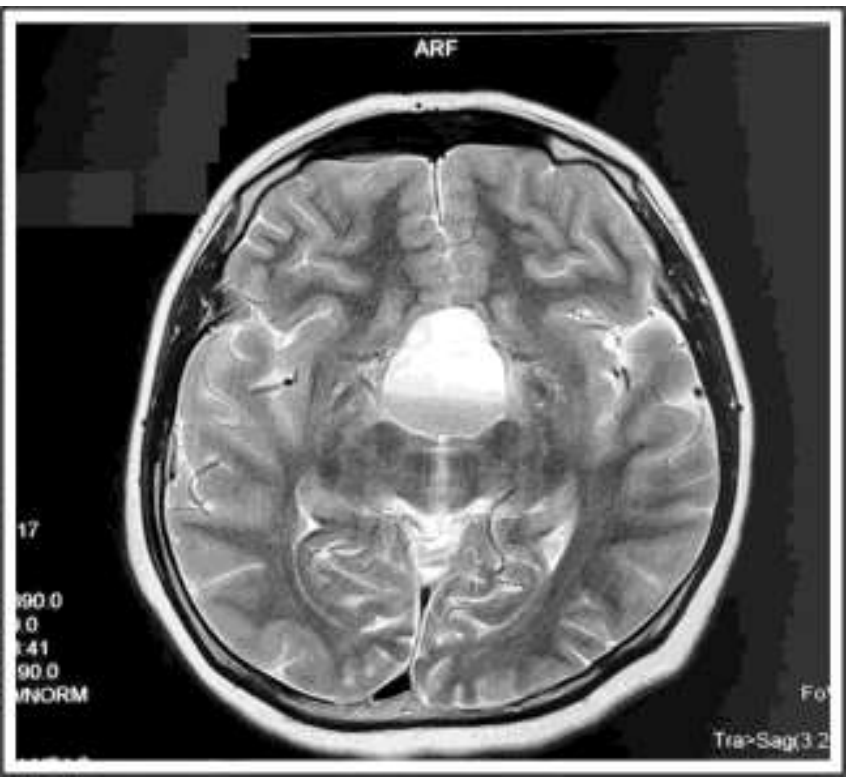

Figure 1: Axial view MRI brain T2 weighted image showing large pituitary adenoma.

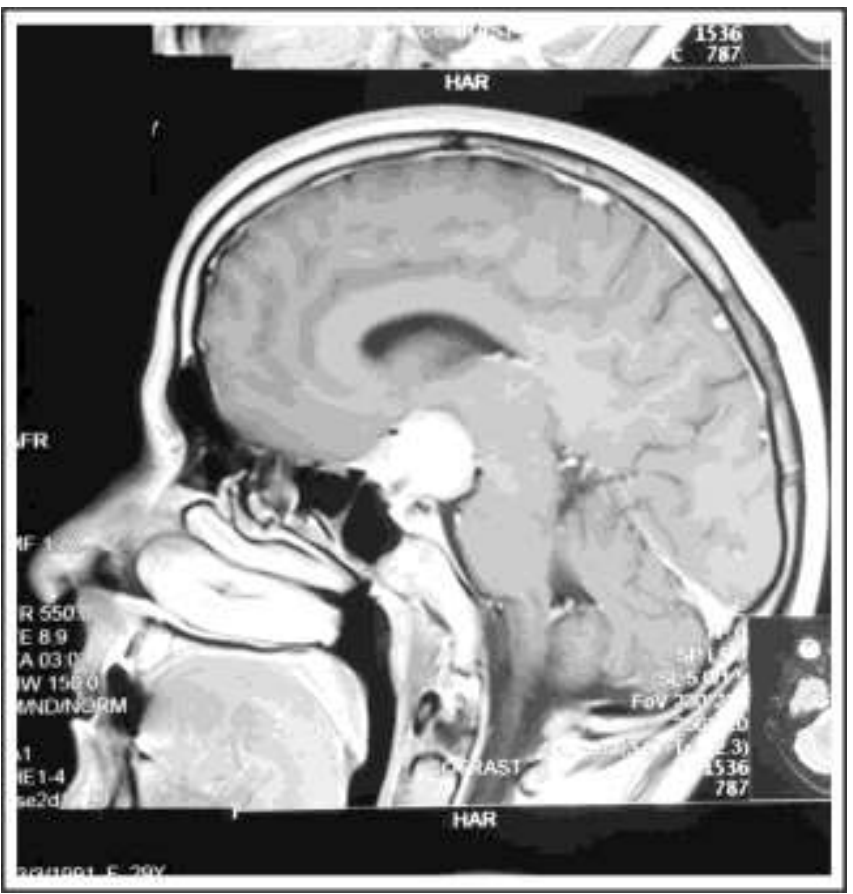

Figure 2: Sagittal MRI with contrast showing Sellar Suprasellar mass. documented. The data was analyzed through statistical IBM software SPSS version 23.

\section{RESULTS}

\section{Background Information \& Clinical Presentation}

Out of 89 patients, 48 (54\%) were male and 41 (46\%) female patients. The mean age was $42 \pm 5$ years. Headache was reported in 82 (92\%) patients as a most common presentation. A decreased visual acuity was reported in 56 (62\%), amenorrhea in 19 (22\%), and acromegaly in 26 (29\%) patients (Table 1).

\section{Surgical Outcome}

Surgical outcome was found good (i.e., 80\%) in patients with microadenomas as compared to patients with macroadenomas (61\%). Whereas, tumors invading the cavernous sinus had a poor outcome, where only $22 \%$ improvement was observed (Table 1). Overall, the early surgical improvement in symptoms was achieved in $72 \%$ of patients.

\section{Complications}

The most common complication was the transient diabetes insipidus followed by CSF leak and postop hematoma. The mortality reported in 5 (5.6\%) patients.

Table 1: Clinical Presentation and Surgical Outcomes $\mathrm{n}=89$.

\begin{tabular}{|ll|} 
Clinical Presentation & \\
Headache & $92 \%$ \\
Decreased Visual Acuity & $62 \%$ \\
Amenorrhea & $22 \%$ \\
Acromegaly & $29 \%$ \\
Status of Surgical Outcome & \\
Microadenomas & $80 \%$ (Good) \\
Macroadenomas & $61 \%$ (Satisfactory) \\
Tumors Invading the Cavernous Sinus & $22 \%$ (Poor) \\
\hline
\end{tabular}
http//www.pakjns.org 


\section{DISCUSSION}

Pituitary tumors are quite challenging sellar region lesions. Surgery has improved tremendously over the last millennium. The most revolutionary development has been the use of endoscopy. ${ }^{10}$ The current study reported the retrospective clinical outcome and complications of endoscopic endonasal transsphenoidal surgery (ETSS) for pituitary adenomas in our clinical setting of Neurosurgery Prime Teaching Hospital. An early surgical improvement related to the reported symptoms was achieved in $72 \%$ of patients. The majority of patients reported a good surgical outcome in patients with microadenomas. The most common complication was the transient diabetes insipidus followed by CSF leak and post-op hematoma. We found that the headache was the most common clinical presentation. The mortality reported in only $5.6 \%$ of patient.

Pinar et al $(2015)^{7}$ included 32 patients in the age range between 23 - 74 years. In their study, $68.8 \%$ of patients had functioning adenomas and $31 \%$ of patients had nonfunctioning tumors. $62.5 \%$ had macroadenomas and $37.5 \%$ had microadenomas. The cavernous sinus extension and suprasellar extension were radiologically seen in $60 \%$ of those having macroadenomas. CSF leakage occurred in only three patients and two patients developed diabetes insipidus. In a study by Gondim et al (2015), ${ }^{10}$ endoscopic surgery was performed in 55 patients age 70 between 70 and 84 years. These patients were followed up for an average of 50 months. $69 \%$ of patients had visual impairment, $29 \%$ had headaches, and $11 \%$ had complete ophthalmoplegia. A 3 score of the American Society of Anesthesiologists was seen in the elderly patients and, it did not have any effect on the surgical extent of resection (EOR) or duration of stay in hospital. Complications were more common in elderly patients with age more than 60 years. They reported that $9 \%$ of patients had CSF leaks, $3.6 \%$ of patients had diabetes insipidus, $7.2 \%$ had refractory hypertension, $1.8 \%$ had a myocardial infarction and one had died. The new anterior pituitary deficit was seen postoperatively in younger patients more commonly as compared to the elderly, as statistically insignificant.

A recent study conducted by Pereira et al (2020) ${ }^{11}$ also evaluated demographics, outcomes, and complications after surgery of nonfunctioning tumors in elderly versus nonelderly patients. In their study, 294 patients were elderly and 614 were non-elderly. Patients' sex, tumor size, and invasion of cavernous sinus were found similar in the two groups. Post-surgical outcomes like duration of admission, EOR, leakage of CSF requiring repair, re-admission within 30 days, rate of infection, and development of new hypopituitarism were also very similar. Adjuvant radiation was not readily given to elderly patients neither were they re-operated as opposed to younger adults. They found that the post-operative Diabetes Insipidus (DI) occurred less commonly in the elderly group as compared to the non-elderly group. Postoperative hyponatremia was $26.7 \%$ as compared to $16.4 \%$ in younger patients. The development of new neurological deficits was also less common in the elderly group. A sub-analysis of the elderly group highlighted that those having higher scores in the Charlson comorbidity index had similar outcomes in the younger group, with the exception of higher DI rates. Peaks and troughs of postoperative serum sodium levels were seen on the third day and ninth day in the elderly group, while in the non-elderly group these were noticed on the second day 2 and 8th of surgery. Pereira et al $(2020)^{11}$ reported that for nonfunctioning pituitary adenomas, the procedure of TSS is safe and has a low incidence of complications.

Jang et al $(2016)^{12}$ reported that $15.4 \%$ of patients developed complications postoperatively. Diabetes insipidus was found to occur temporarily in 14 cases and only 3 patients developed it permanently. Nine patients had 
syndrome of inappropriate antidiuretic hormone (SIADH), 6 cases had CSF leaks. Only one patient died due to the procedure. Progression occurred in $27.8 \%$ of patients which took an average period of 23.7 months. The mean follow-up period was 68.5 months. The average duration of hospitalization was 4.4 ( \pm 1.6$)$ days. Gondim et al $(2010)^{13}$ conducted a study to determine the efficacy and safety of endoscopic excision for pituitary tumors. They included 288 consecutive patients who had endonasal endoscopic surgeries for the removal of adenomas. They did not report any mortality from the procedure ETSS. They concluded that the ETSS approach is an acceptable and best alternative to the microscopic procedure, as it is less invasive and includes fewer complications. This procedure also gives an excellent tumor removal rate.

\section{CONCLUSION}

The overall rate of early surgical improvement in symptoms was observed in $72 \%$ of patients. The majority of the patients reported a good surgical outcome in patients with microadenomas. We conclude that endoscopic endonasal transsphenoidal surgery is a safe, less invasive, cosmetically effective technological advancement for pituitary adenomas.

\section{RECOMMENDATIONS}

There are certain significant advantages of endoscopic surgery, however, it does not totally oust microsurgery, which has certain advantages too. More studies are required as prospective randomized trials to evaluate the profoundness of endoscopy in the resection of pituitary adenomas. Although, the tool of ETSS provides satisfactory results, however, it mainly deals with the reduction of large adenomas. ${ }^{10,13}$ The study results can help in discussions regarding operation and complications of endoscopic endonasal transsphenoidal surgery patients with pituitary adenoma.

\section{REFERENCES}

1. Ezzat $\mathrm{S}$, Asa SL, Couldwell WT, Barr CE, Dodge WE, Vance $M L$, et al. The prevalence of pituitary adenomas: a systematic review. Cancer: Interdisciplinary International Journal of the American Cancer Society, 2004; 101 (3): 613-9.

2. Akbari $H$, Malek $M$, Ghorbani $M$, Ramak Hashemi SM, Khamseh ME, Zare Mehrjardi A, et al. Clinical outcomes of endoscopic versus microscopic transsphenoidal surgery for large pituitary adenoma. British Journal of Neurosurgery, 2018; 32 (2): 2069.

3. Cavallo LM, Solari D, Tasiou A, Esposito F, de Angelis M, D'Enza Al, et al. Endoscopic endonasal transsphenoidal removal of recurrent and regrowing pituitary adenomas: experience on a 59patient series. World Neurosurgery, 2013; 80 (3-4): 342-50.

4. Rehman L, Rehman UL, Jabeen R, Rizvi R. Endoscopic Trans-Sphenoidal surgery; Efficacy and response in Pituitary Adenoma. Pakistan Journal of Medical Sciences, 2018; 34 (2): 412.

5. Guvenc G, Kizmazoglu C, Pinar E, Imre A, Kaya I, Bezircioglu $\mathrm{H}$, et al. Outcomes and complications of endoscopic versus microscopic transsphenoidal surgery in pituitary adenoma. Journal of Craniofacial Surgery, 2016; 27 (4): 1015-20.

6. Wang F, Zhou T, Wei S, Meng X, Zhang J, Hou Y, et al. Endoscopic endonasal transsphenoidal surgery of 1,166 pituitary adenomas. Surgical Endoscopy, 2015; 29 (6): 1270-80.

7. Pinar E, Yuceer N, Imre A, Guvenc G, Gundogan O. Endoscopic endonasal transsphenoidal surgery for pituitary adenomas. Journal of Craniofacial Surgery, 2015; 26 (1): 201-5.

8. Tataranu L, Gorgan M, Ciubotaru V, Dediu A, Ene B, Paunescu D, et al. Endoscopic Endonasal Transsphenoidal Approach in the Management of Sellar and Parasellar Lesions: and Standard Surgical Technique (Part I). Romanian Neurosurgery, 2010: 52-63.

9. Cappabianca P, Cavallo LM, De Divitiis E. Endoscopic endonasal transsphenoidal surgery. Neurosurgery, 2004; 55 (4): 933-41.

10. Gondim JA, Almeida JP, de Albuquerque LAF, Gomes E, Schops M, Mota Jl. Endoscopic endonasal transsphenoidal surgery in elderly 
patients with pituitary adenomas. Journal of Neurosurgery, 2015; 123 (1): 31-8.

11. Pereira MP, Oh T, Joshi RS, Haddad AF, Pereira KM, Osorio RC, et al. Clinical characteristics and outcomes in elderly patients undergoing transsphenoidal surgery for nonfunctioning pituitary adenoma. Neurosurgical Focus, 2020; 49 (4): E19.

12. Jang JH, Kim KH, Lee YM, Kim JS, Kim YZ. Surgical results of pure endoscopic endonasal transsphenoidal surgery for 331 pituitary adenomas: a 15-year experience from a single institution. World Neurosurgery, 2016; 96: 545-55.

13. Gondim JA, Schops $M$, de Almeida JPC, de

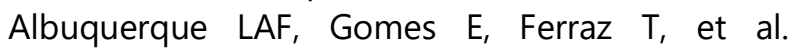
Endoscopic endonasal transsphenoidal surgery: surgical results of 228 pituitary adenomas treated in a pituitary center. Pituitary, 2010; 13 (1): 68-77.

\section{Additional Information}

Disclosures: Authors report no conflict of interest.

Ethical Review Board Approval: The study was retrospective. No approval required.

However, institutional ethical rules were followed.

\section{Conflicts of Interest:}

In compliance with the ICMJE uniform disclosure form, all authors declare the following:

Financial Relationships: All authors have declared that they have no financial relationships at present or within the previous three years with any organizations that might have an interest in the submitted work.

Other Relationships: All authors have declared that there are no other relationships or activities that could appear to have influenced the submitted work.

\section{AUTHORS CONTRIBUTIONS}

\begin{tabular}{|l|l|l|}
\hline Sr.\# & Author's Full Name & Intellectual Contribution to Paper in Terms of: \\
\hline 1. & Musawer Khan & Analysis of data, study design and methodology. \\
\hline 2. & Arif Hussain & Literature, manuscript writing and data collection. \\
\hline 3. & Mumtaz Ali & Interpretation of results and quality assurer. \\
\hline
\end{tabular}

